\title{
Terahertz Non-Contact Monitoring of Cocoa Butter in Chocolate*
}

\author{
Sebastien Weiller ${ }^{1}$, Tadao Tanabe $^{2}$, Yutaka Oyama ${ }^{2}$ \\ ${ }^{1}$ Ecole des Mines d'Albi, Allée des sciences, Albi, France \\ ${ }^{2}$ Department of Materials Science, Graduate School of Engineering, Tohoku University, Sendai, Japan \\ Email: tadao.tanabe.b1@tohoku.ac.jp
}

How to cite this paper: Weiller, S., Tanabe, T. and Oyama, Y. (2018) Terahertz Non-Contact Monitoring of Cocoa Butter in Chocolate. World Journal of Engineering and Technology, 6, 268-274. https://doi.org/10.4236/wjet.2018.62015

Received: February 20, 2018

Accepted: May 8, 2018

Published: May 11, 2018

Copyright ( 92018 by authors and Scientific Research Publishing Inc. This work is licensed under the Creative Commons Attribution International License (CC BY 4.0).

http://creativecommons.org/licenses/by/4.0/

(c) (i) Open Access

\begin{abstract}
Chocolate is widely enjoyed in many sweets and foods all over the world. In cocoa butter, fatty acids combine together and give cocoa butter 6 different types of crystals: $\gamma, \alpha, \beta$ (III), $\beta(\mathrm{IV}), \beta(\mathrm{V})$ and $\beta(\mathrm{VI})$. In the industry, the $\beta(\mathrm{V})$ form that is required, is metastable and gives chocolate its marketable properties. The $\beta(\mathrm{VI})$ form is also stable but not desirable, because of fat bloom. The objective of this study is to characterize these polytypes by terahertz $(\mathrm{THz})$ spectroscopy. THz spectroscopy is expected to be a new tool in food industry, as $\mathrm{THz}$ energy corresponds to collective molecular macro-vibrations. Two chocolates from different factories were inspected with optical microscope, $\mathrm{X}$-ray diffraction (XRD) and $\mathrm{THz}$ spectroscopy. Optical microscope showed different surface aspects, XRD showed the same species in the two brands and $\mathrm{THz}$ spectroscopy showed different features. These differences may be due to fatty acids combination of chocolate.
\end{abstract}

\section{Keywords}

Chocolate, Cocoa Butter, Terahertz Spectroscopy, Noncontact Monitoring

\section{Introduction}

Chocolate is an organic edible compound that is made from cocoa bean. It is widely preferred in many sweets and foods all over the world. The average composition of the chocolate is $54 \%$ carbohydrates, $27 \%$ fats, $9 \%$ fiber, $6 \%$ proteins and $1 \%$ water [1]. These fats come from cocoa butter, which is mainly made of three fatty acids: $34.5 \%$ of oleic acid O (mono-unsaturated), $26 \%$ of palmitic acid $\mathrm{P}$ (saturated) and $34.5 \%$ of stearic acid S (saturated). Around $85 \%$ of the total fats are a combination of these three fatty acids in triglyceride fats: POP, POS

${ }^{\star}$ Novel terahertz spectroscopy enables us to identify fatty acids combination of chocolate. 
and SOS [2]. It is those fatty acids that confer cocoa butter, and therefore chocolate, its polytypes properties. 6 different crystals can be distinguished, with several varieties: $\gamma, \alpha, \beta(\mathrm{III}), \beta(\mathrm{IV}), \beta(\mathrm{V})$ and $\beta(\mathrm{VI})$. Because the $\gamma, \alpha$ and $\beta$ are not thermodynamically stable, they are therefore not an issue. In the industry, the $\beta(\mathrm{V})$ form that is required, is metastable and gives chocolate all of the properties that make it marketable: brilliant, appetizing, melting in the mouth and brittle. The $\beta(\mathrm{VI})$ form is also stable and has a melting point higher than the $\beta(\mathrm{V})$ form. However, it is not desired, because of the aspect if giving to the chocolate: fat bloom. Chocolate tempering can overcome this issue. Until now, X-ray diffraction (XRD) was used to characterize the crystal structure of chocolate [2] [3] [4] [5]. Terahertz ( $\mathrm{THz})$ wave bridges microwave and light, and its frequency corresponds to the weak molecular bonding. $\mathrm{THz}$ spectroscopy has promising potential for the identification of macromolecules such as polymer and biomolecules. Unlike XRD, THz spectroscopy is not hurting for human tissues, due to its low energy. It is also a non-destructive analysis tool. $\mathrm{THz}$ time-domain spectroscopy (THz-TDS) has been used on chocolate, but only for non-destructive detection of contaminations in chocolate [6]. The non-destructive evaluation can therefore be a new tool for in-line quality monitoring of chocolate in factories. The goal of this study is to try to characterize the different polytypes combination of cocoa butter in chocolate with $\mathrm{THz}$ spectroscopy.

\section{Materials and Methods}

The optical system used for $\mathrm{THz}$ spectroscopy was composed with a $1064 \mathrm{~nm}$ Q-switch pulsed Nd:YAG laser as pump for Cr:Forsterite lasers, as shown in Figure 1. The Cr:Forsterite laser emits a light source at $1240 \mathrm{~nm}$ and a tunable light between $1240 \mathrm{~nm}$ and $1280 \mathrm{~nm}$. The light sources meet in a GaP crystal with non-collinear phase matching, so as to generate a frequency-tunable $\mathrm{THz}$ wave based on difference frequency mixing [7]. The wave was then detected by using a $4.2 \mathrm{~K}$ Si bolometer.

Two chocolates where chosen from factories of $\mathrm{L}$ and $\mathrm{H}$. Three types of samples were prepared. Type 1 samples were $1 \times 1 \mathrm{~cm}^{2}$ surface pieces. Type $1 \mathrm{sam}$ ples were examined with an optical microscope. Figure 2(a) shows surface's morphology. Type 2 samples were around $1 \mathrm{~mm}$ length pieces, cut from chocolate bar with a cutter blade. Type 2 samples were used in XRD employing nickel-filtered $\mathrm{CuKa}$ radiation. These samples were made in order to apply the XRD powder measurement method. Type 3 samples were super thin cutter-scratched pieces as shown in Figure 2(b). Chocolate bar's edges were scratched smoothly with a cutter blade. Type 3 samples were put in a PEEK (Polyetheretherketone) film used for $\mathrm{THz}$ spectroscopy. PEEK film has no absorption peak in the range of frequency used ( $2-3 \mathrm{THz}$ ). PEEK film without chocolate was used so as to measure the background. Total thickness was around $5 \mathrm{~mm}$, with 10 particles

$\mathrm{mL}^{-1}$. Type 3 samples were made because type 1 and type 2 samples were too thick for THz spectroscopy. 


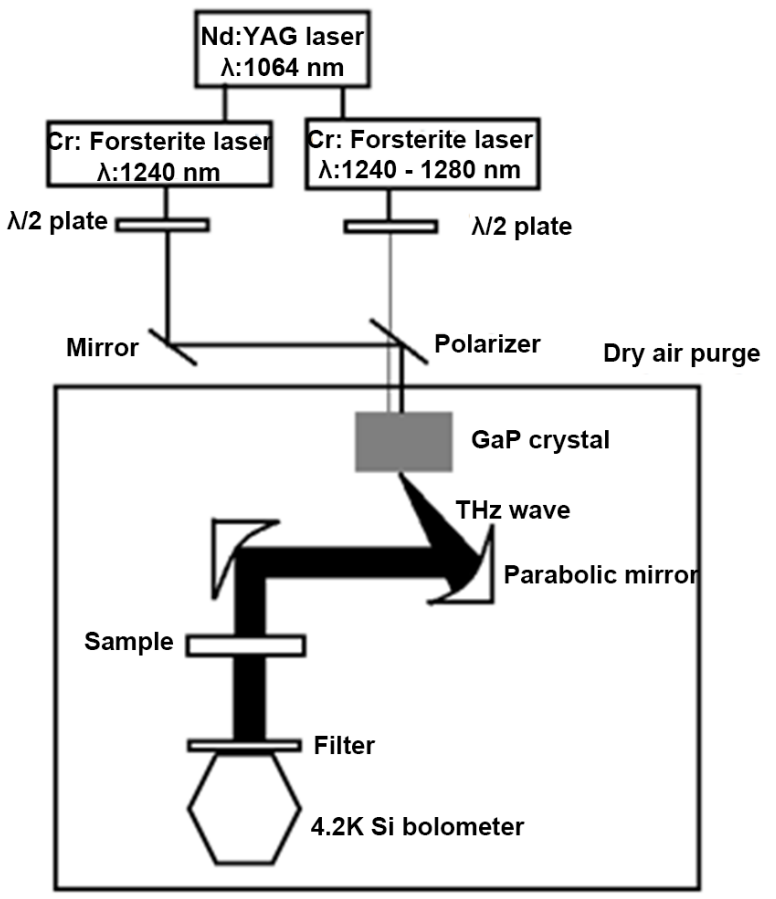

Figure 1. Schematic drawing of optical configuration for THz spectroscopy.
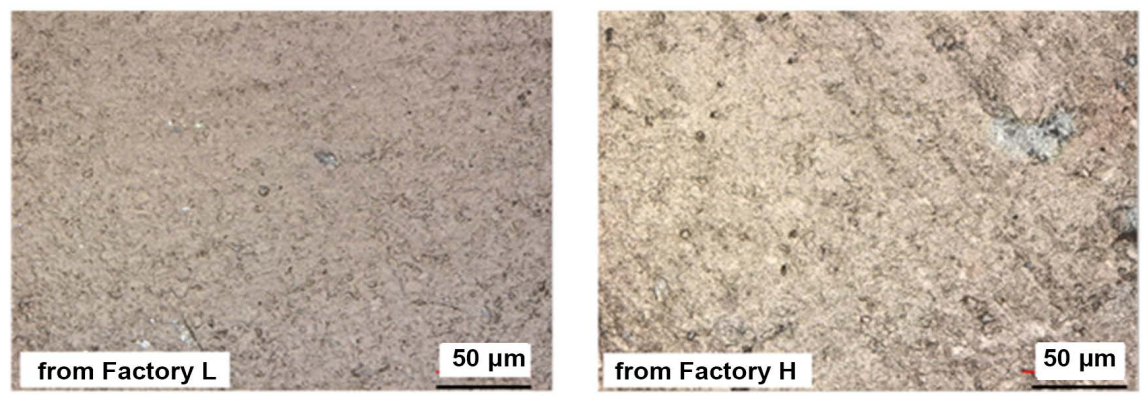

(a)

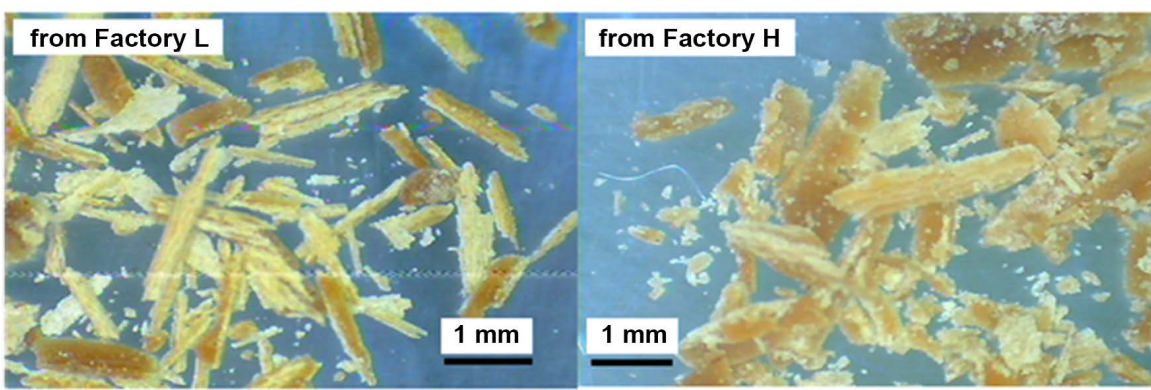

(b)

Figure 2. Surface morphology of chocolates from factories L and H. (a) Type 1 for optical microscope and (b) Type 3 for THz spectroscopy.

\section{Results and Discussion}

Type 1 samples surface morphology showed significant differences between the factories. Visually, factory L samples appear to be smoother. This is confirmed 
by measuring $\mathrm{Ra}$ and $\mathrm{Rq}$. For factory L samples, $\mathrm{Ra}=0.42 \mu \mathrm{m}$ and $\mathrm{Rq}=0.55 \mu \mathrm{m}$ in average. For factory $\mathrm{H}$ samples, $\mathrm{Ra}=0.77 \mu \mathrm{m}$ and $\mathrm{Rq}=0.92 \mu \mathrm{m}$ in average. Besides, some traces of fat bloom (6 clear spots) can be found visually on factory $\mathrm{H}$ samples, whereas only 1 is visible on $\mathrm{L}$ samples.

Figure 3 shows XRD profiles of factories L and H. XRD profiles of type 2 samples show the same species with Sugar, $\beta(\mathrm{V})$ and $\beta(\mathrm{VI})$ crystals. Peaks were assigned by calculating the $\mathrm{h}, \mathrm{k}$ and $\mathrm{l}$ diffraction's parameters of sugar, $\beta(\mathrm{V})$ and $\beta$ (VI) crystals [8] [9]. Other species may be contained in the samples, but there were not determined.

$\mathrm{THz}$ spectra of type 3 samples show differences. An absorption slope can be observed with factory $\mathrm{H}$ samples in the $2.09-2.93 \mathrm{THz}$ range as shown in Fig. 4 . Considering Rayleigh scattering, particles whose size is around $0.25 \mathrm{~mm}$ for factory $\mathrm{H}$ and $0.19 \mathrm{~mm}$ for factory $\mathrm{L}$ could cause this absorption slope. Calculations were made considering the refractive index of cocoa butter (1.46) and 10 particles $\mathrm{mL}^{-1}[10]$. The definition of the absorbance is

$$
A=\log _{10}\left(\frac{I}{I_{0}}\right)
$$

$I$ and $I_{0}$ are respectively the intensities of the detected beam and the incident beam. I can be expressed with the Beer-Lambert law

$$
I=I_{0} \mathrm{e}^{-(\alpha+N \sigma) x}
$$

where $\alpha$ is a coefficient representing absorption, $N$ the volume density of particles, $x$ the position in the sample and $\sigma$ the cross section of the particles. Rayleigh scattering formula is as follows [11]:

$$
\sigma=\frac{2 \pi^{5}}{3} \cdot \frac{d^{6}}{\lambda^{4}} \cdot\left(\frac{m^{2}-1}{m^{2}+2}\right)^{2}
$$

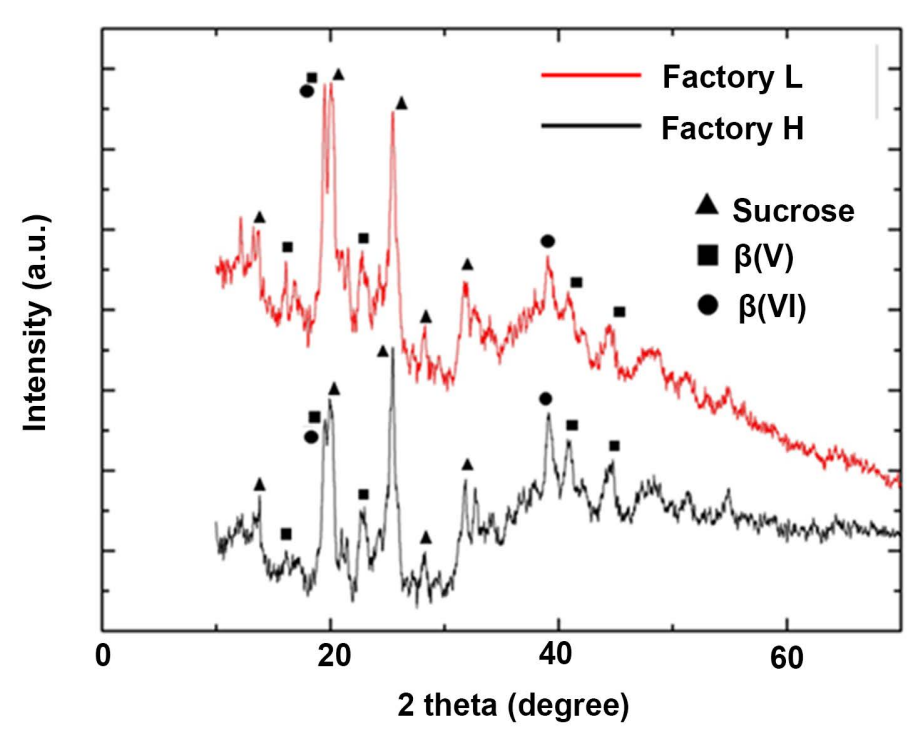

Figure 3. XRD profiles of chocolates from factory L (black) and $\mathrm{H}$ (red). 


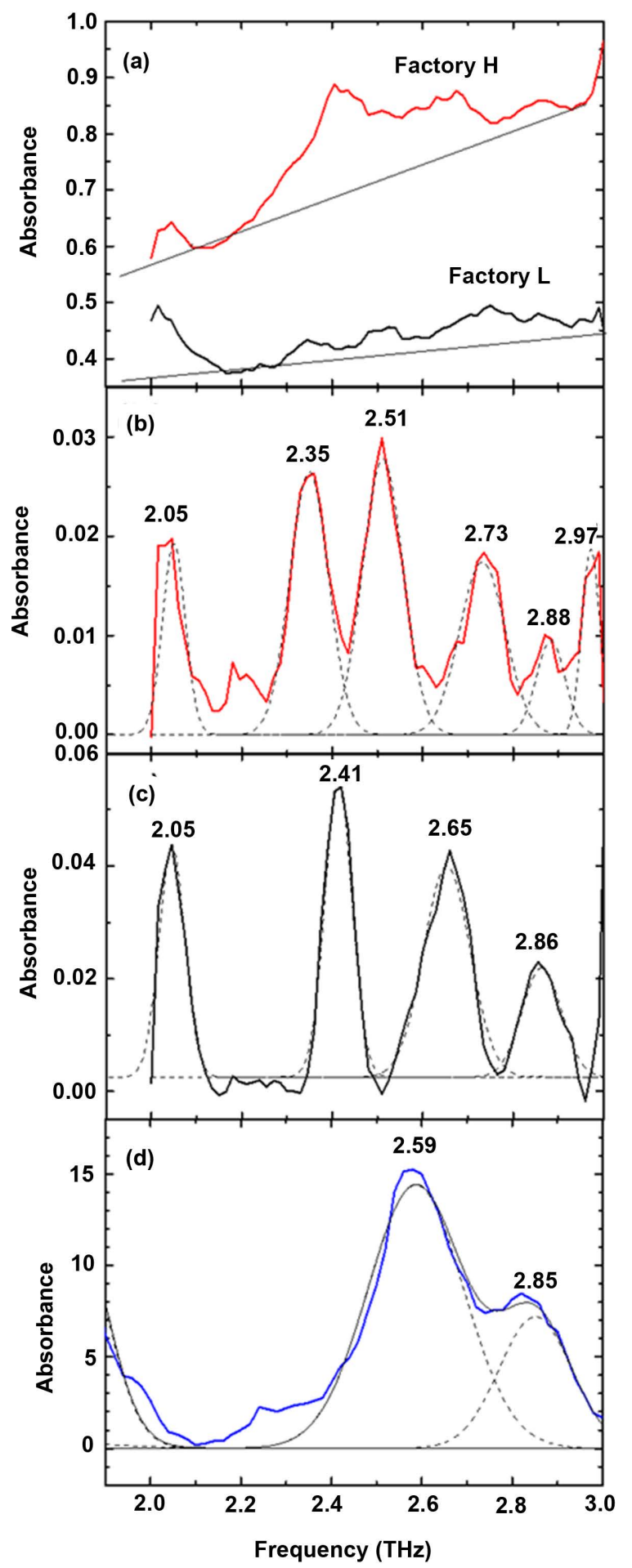

Figure 4. (a) $\mathrm{THz}$ spectra of chocolates from factory $\mathrm{L}$ (black) and $\mathrm{H}$ (red). Baseline correction and peaks separations for $\mathrm{THz}$ spectra from factory $\mathrm{L}(\mathrm{b})$ and $\mathrm{H}$ (c). $\mathrm{THz}$ spectrum of sucrose [12] (d).

where $d$ is the diameter of the particles, $\lambda$ the wavelength of the incident light, and $\mathrm{m}$ the refractive index of the sample. Assuming that $\alpha$ is constant, and with 
$x=1$ the bulk length of the sample, we can calculate an estimation the size of the particles causing the scattering, by calculating the difference between two absorbance values.

$$
d=\sqrt[6]{\frac{\Delta A \cdot 3 \cdot \ln (10) \cdot \Delta\left(\lambda^{4}\right)}{2 \cdot \pi^{5} \cdot N \cdot l} \cdot\left(\frac{m^{2}+2}{m^{2}-1}\right)^{2}}
$$

where $\Delta A$ and $\Delta \lambda$ are the differences of the absorbance and wavelength at the beginning and the end of the slope. Baseline correction and peaks separation that highlighted two peaks in common for the two brands, at $2.05 \mathrm{THz}$ and around $2.88 \mathrm{THz}$.

In addition to that, Figure 4 presents chocolate samples' peaks. Factory L samples' shows peaks at $2.35 \mathrm{THz}, 2.51 \mathrm{THz}, 2.73 \mathrm{THz}$ and $2.97 \mathrm{THz}$. Factory H samples have peaks at $2.41 \mathrm{THz}$ and $2.65 \mathrm{THz}$. Peaks have not been attributed to any species. However, the peaks at 2.51 and $2.88 \mathrm{THz}$ can be assigned to sucrose, as this specie also presents peaks around 2.59 and $2.85 \mathrm{THz}$ [12]. The differences between the spectra of $\mathrm{L}$ and $\mathrm{H}$ may be explained with formation and migration of $\beta(\mathrm{VI})$ crystals combined with fatty acids, which is seen in the XRD patterns and terahertz spectra, respectively. The energy of $\mathrm{THz}$ wave corresponds to molecular interactions such as hydrogen bonding, van der Waals interactions and lattice interactions. Depending on how advanced this phenomenon is, spectra can show differences. $\mathrm{L}$ and $\mathrm{H}$ do not have many peaks in common, but both present peaks very close from each other.

Terahertz spectroscopy can therefore be a new tool to control tempering in chocolate factories. The control is important for cocoa butter crystallization [13]. Even packed in films such as paper with high transmittance of terahertz wave, chocolate can still be monitored by using terahertz spectroscopy. Elucidation of terahertz vibrational modes should be elucidated for terahertz applications of food and pharmacy [14].

\section{Conclusion}

The cocoa butter polymorphs of $\beta(\mathrm{V})$ and $\beta(\mathrm{VI})$ have been determined in chocolate by XRD. Surface morphology analysis highlighted fat bloom deposit on factory $\mathrm{H}$ samples. Terahertz spectroscopy showed difference between factories $\mathrm{L}$ and $\mathrm{H}$. These differences may be due to formation and migration of $\beta(\mathrm{VI})$ crystals on the surface of factory $\mathrm{H}$ samples, which can be elaborated more by terahertz measurements of chocolate at each step in the tempering process.

\section{Acknowledgements}

We acknowledge an exchange program between Tohoku University and Ecole des Mines d'Albi-Carmaux, Cooperative Laboratory Study Program (COLABS).

\section{References}

[1] Corler, B. (1992) Le chocolat: Fabrication, composition, valeur nutritionnelle, sa 
place dans l'alimentation humaine. Ph.D. Thesis.

[2] Fryer, P. and Pinschower, K. (2000) The Materials Science of Chocolate. MRS/Bulletin, 25, 25-29. https://doi.org/10.1557/mrs2000.250

[3] Loisel, C., Adenier, H., Chaveron, H., Keller, G. and Ollivon, M. (2002) Le blanchissement du chocolat: Mécanismeetprévention. 6ème Colloque de IAlliance 7/CEDUS, 12 February 2002, 55-65.

[4] Willie, R.L. and Lutton, E.S. (1966) Polymorphism of Cocoa Butter. Journal of the American Oil Chemists' Society, 43, 491-496. https://doi.org/10.1007/BF02641273

[5] Guthrie, S.E., Mazzanti, G. and Idziak, S.H.J. (2005) X-Ray Phase Identification of Chocolate Is Possible without the Removal of Sugar. European Journal of Lipid Science and Technology, 107, 656-659. https://doi.org/10.1002/ejlt.200501178

[6] Jördens, C., Rutz, F. and Koch, M. (2006) Quality Assurance of Chocolate Products with Terahertz Imaging. European Conference for Non Destructive Technique, Berlin, 25-29 September 2006, Poster 67. http://www.ndt.net/article/ecndt2006/doc/P67.pdf

[7] Tanabe, T. and Oyama, Y. (2011) Frequency-Tunable Coherent THz-Wave Pulse Generation Using Two Cr:Forsterite Lasers with One Nd:YAG Laser Pumping and Applications for Non-Destructive THz Inspection. In: Krzysztof Jakubczak, K., Ed., Laser Systems for Applications, InTech, Inc., Chap. 6, 119-136. https://doi.org/10.5772/23468

[8] van Mechelen, J.B., Peschar, R. and Schenk, H. (2006) Structures of Mono-Unsaturated Triacylglycerols. I. The $\beta_{1}$ Polymorph. Acta Crystallographica Section B, 62, 1121-1130. https://doi.org/10.1107/S0108768106037074

[9] van Mechelen, J.B., Peschar, R. and Schenk, H. (2006) Structures of Mono-Unsaturated Triacylglycerols. II. The $\beta_{2}$ Polymorph. Acta Crystallographica Section B, 63, 1131-1138. https://doi.org/10.1107/S0108768106037086

[10] Padilla, F.C., Liendo, R. and Quintana, A. (2000) Characterization of Cocoa Butter Extracted from Hybrid Cultivars of Theobroma cacao L. Archivos Latinoamericanos De Nutricion, 50, 200-205.

[11] Lord Rayleigh, F.R.S. (1879) XXXI. Investigations in Optics, with Special Reference to the Spectroscope. The London, Edinburgh, and Dublin Philosophical Magazine and Journal of Science Series 5, 8, 261-274. https://doi.org/10.1080/14786447908639684

[12] Nishizawa, J., Suto, K., Sasaki, T., Tanabe, T. and Kimura, T. (2003) Spectral Measurement of Terahertz Vibrations of Biomolecules Using a GaP Terahertz-Wave Generator with Automatic Scanning Control. Journal of Physics D: Applied Physics, 36, 2958-2961. https://doi.org/10.1088/0022-3727/36/23/015

[13] Rigolle, A., Foubert, I., Hettler, J., Verboven, E., Martens, A., Demuynck, R. and Abeele, K.V.D. (2016) Insight in Ultrasonic Shear Reflection Parameters by Studying Temperature and Limonene Influence on Cocoa Butter Crystallization. Innovative Food Science \& Emerging Technologies, 33, 289-297.

https://doi.org/10.1016/j.ifset.2015.12.004

[14] Sasaki, T., Sakamoto, T. and Otsuka, M. (2018) Detection of Impurities in Organic Crystals by High-Accuracy Terahertz Absorption Spectroscopy. Analytical Chemistry, 90, 1677-1682. https://doi.org/10.1021/acs.analchem.7b03220 